\title{
Trends in baseline CD4 count at presentation to care among HIV-positive patients in Sungai Buloh Hospital, Malaysia
}

\author{
Chee Loon Lim, Suresh Kumar \\ Department of Medicine, Sungai Buloh Hospital, Malaysia
}

\begin{abstract}
Introduction: Many people living with human immunodeficiency virus (HIV) do not enter healthcare until late in their infection course. We analysed the trends in baseline CD4 count among HIV patients in Sungai Buloh Hospital, Malaysia.

Material and methods: A retrospective cohort study was conducted from the Malaysian AIDS Treatment Cohort (MATCH) database of HIV-positive patients registered in our HIV clinic between 2007 and 2016.

Results: Out of 8757 patients, $84.5 \%$ were male. Heterosexual (38.2\%) and homosexual (36.4\%) contacts were the predominant HIV risk factors. Approximately $44 \%$ of patients presented late to care (CD4 $<200$ cells/ $\mu \mathrm{l}$ ). The overall median baseline CD4 cell count was 235 cells/ $\mu \mathrm{l}$. The yearly median baseline CD4 cell count increased steadily from 176 cells/ $\mu$ in 1997 to a peak of 271 cells/ $\mu$ in 2015 ( $p$ for trend $<0.001$ ). By HIV exposure risks, homosexual risk group consistently had the highest median baseline CD4 cell count, followed by heterosexual and intravenous drug use (IVDU) risk groups. The proportion of late presenters significantly decreased over time from $57.0 \%$ in 2007 to $44.0 \%$ in 2016 ( $p$ for trend < 0.001).

Conclusions: The trends in baseline CD4 cell counts are improving, but the proportion of late presenters is still significant. Innovative strategies are imperative to identify HIV infected individuals early and link them promptly to HIV care.
\end{abstract}

HIV AIDS Rev 2019; 18, 2: 85-91 DOI: https://doi.org/10.5114/hivar.2019.86372

Key words: HIV, CD4, baseline, trends, Malaysia.

\section{Introduction}

Human immunodeficiency virus (HIV) infection is recognized as a chronic disease largely due to the effectiveness of antiretroviral therapy (ART). Early initiation of ART at a higher level of CD4 cell counts is one of the predictors of immunologic and virological success after treatment [1], which prevents both disease progression and HIV transmission to sexual partners [2].

Address for correspondence: Dr. Chee Loon Lim, Department of Medicine, Sungai Buloh Hospital, Malaysia, phone: +60133620081, e-mail: stevenlimcl@gmail.com

Malaysia has shown considerable progress in treatment and control of HIV/acquired immunodeficiency syndrome (AIDS). The policy to provide free first line ART to all Malaysian citizens in 2006 marked an important milestone in the national response to the HIV epidemic. By the end of 2015, there were an estimated 92,895 people living with HIV (PLWH) and about 25,700 (28\%) of them on life-saving ART [3]. Despite the availability of free ART and integrated HIV care services in most of the tertiary hospitals and pri-

Article history:

Received: 30.09 .2018

Received in revised form: 26.11.2018

Accepted: 19.04.2019

Available online: 05.06.2019
International Journal of HIV-Related Problems

HIV \& AIDS

R e vi e w 
mary care clinics with family physicians, a substantial number of PLWH still do not enter health care until late in their infection course.

Over the history of the HIV epidemic, the importance of early diagnosis and prompt engagement in medical care has been a recurring theme. About $15 \%$ to $43 \%$ of PLWH in the developed world present at clinics for care with advanced or severe disease (WHO stage 3 or 4, CDC category B or C or CD4 $\leq 200$ cells/ $\mu$ l) [4-16]. Factors associated with late presentation in the developed world include older age, male gender, lower income, low degree of education and high risk behaviour such as intravenous drug use (IVDU) and alcohol use [12, 16-22]. However, little is known in developing countries like Malaysia about the proportion and characteristics of PLWH who present late for HIV care. There is a dearth of studies at the national level which assess the timeliness of treatment access among PLWH. Identifying the proportion of late presenters at clinics and predictors of late presentation could assist local health professionals and policy makers in allocating resources to different types of HIV care services, and in designing interventions to overcome barriers to early HIV care.

The objective of the present study is to analyze the trends in baseline CD4 count among PLWH in Sungai Buloh Hospital, a major HIV referral centre situated in the state of Selangor, Malaysia. We believe the trends in baseline CD4 count of PLWH at first presentation to HIV clinics can be used as an indicator to assess the effectiveness of national HIV awareness campaigns, expansion of HIV screening and ART treatment services, and most importantly efforts made to improve the linkages between primary care, HIV related non-governmental organizations (NGOs) and the HIV treatment centres.

\section{Material and methods}

\section{Study setting and population}

This is a retrospective cohort study conducted at the HIV clinic in Sungai Buloh Hospital. Our study population consisted of HIV-positive patients aged $\geq 12$ years old who were ART naive and registered in our HIV clinic between $1^{\text {st }}$ January 2007 and $31^{\text {st }}$ December 2016. Blood samples were routinely taken from all newly registered patients for baseline CD4 cell counts. Patients who were started on ART prior to HIV clinic registration were excluded.

\section{Data collection and definitions}

Baseline CD4 cell count at first clinic visit, demographic data including gender, age, ethnicity, HIV exposure risk and occupation were extracted from the Malaysian AIDS Treatment Cohort (MATCH) database. Established in 2014, MATCH is a multi-centre observational cohort study enrolling all patients receiving ART in 10 tertiary hospitals in Malaysia, of which Sungai Buloh Hospital has the largest cohort. Late presentation to care was defined as a CD4 cell count $<200$ cells $/ \mu$ l while non-late presentation to care was defined as a CD 4 cell count $\geq 200$ cells $/ \mu$ l.

\section{Statistical analysis}

Baseline values were compared using the $\chi^{2}$ test for categorical variables and Mann-Whitney or Kruskal-Wallis test for continuous variables. Trends in median CD4 cell count at first presentation to care by year and the proportion of late presenters by year were evaluated using Kendall's tau-b correlation coefficient and $\chi^{2}$ linear by linear association methods, respectively. IBM SPSS Statistics software version 22 was used for all statistical analyses.

\section{Results}

\section{Patient demographics}

There were 8894 new HIV positive patients registered in our HIV clinic. We excluded 109 patients who were taking ART before being referred to our clinic for continuation of care and 28 patients who did not have a record of baseline CD4 cell count. A total of 8757 patients were included in the analysis. Baseline characteristics of all patients stratified by late and non-late presentation to care are shown in Table 1.

The majority $(84.5 \%)$ of the patients were male. Approximately $40 \%$ of them were 30 years old or younger with a mean (standard deviation, SD) age of 34.8 (9.8) years. Ethnic Malays comprised $43.7 \%$ of the cohort. Heterosexual (38.2\%) and homosexual (36.4\%) contacts were the predominant HIV exposure risk factors. Most of the patients came from the non-professional occupational group (42.0\%). A total of $3880(44.3 \%)$ patients were classified as presenting late to care. The distributions of age group, HIV exposure risk factor, occupational group and year of first presentation to care were significantly different among patients with late presentation compared to those with non-late presentation $(p \leq 0.001$ for all).

\section{Median CD4 count and trends}

The overall median (interquartile range - IQR) CD4 cell count at first presentation to care was 235 (340) cells/ $\mu$ l. Median CD4 count was 52 (103) cells/ $\mu$ l among patients with late presentation and 381 (230) cells/ $\mu$ l among patients with non-late presentation. The median baseline CD4 count at presentation to care was further stratified by characteristics of patients in Table 2. Females and males had a median CD4 count of 243 cells $/ \mu \mathrm{l}$ and 233 cells $/ \mu \mathrm{l}$, respectively $(p=0.009)$. The median CD4 count also differed significantly according to age group, ethnicity, HIV exposure risk factors and occupational group ( $p<0.001$ for all). The highest median CD4 counts were noted in patients aged $\leq 30$ years old (296 cells/ $\mu \mathrm{l})$ and the student group (349 cells/ $\mu \mathrm{l})$. Patients involved in intravenous drug use (IVDU) had the lowest median CD4 count of 161 cells/ $\mu$ l. 
Table 1. Patient baseline characteristics

\begin{tabular}{|c|c|c|c|c|}
\hline Characteristics & $\begin{array}{l}\text { All patients, } \\
n=8757(\%)^{\mathrm{a}}\end{array}$ & $\begin{array}{l}\text { Patients with late presentation } \\
\text { to care, } n=3880(\%)^{\mathrm{b}}\end{array}$ & $\begin{array}{l}\text { Patients with non-late presentation } \\
\text { to care, } n=4877(\%)^{\mathrm{b}}\end{array}$ & $p^{c}$ \\
\hline \multicolumn{4}{|l|}{ Gender } & \multirow[t]{3}{*}{0.113} \\
\hline Male & $7399(84.5)$ & $3305(44.7)$ & $4094(55.3)$ & \\
\hline Female & $1358(15.5)$ & $575(42.3)$ & $783(57.7)$ & \\
\hline \multicolumn{4}{|l|}{ Age group (years) } & \multirow[t]{5}{*}{$<0.001$} \\
\hline$\leq 30$ & $3438(39.3)$ & $1108(32.2)$ & $2330(67.8)$ & \\
\hline $31-40$ & $3077(35.1)$ & $1545(50.2)$ & $1532(49.8)$ & \\
\hline $41-50$ & $1600(18.3)$ & $853(53.3)$ & $747(46.7)$ & \\
\hline$\geq 51$ & $642(7.3)$ & $374(58.3)$ & $268(41.7)$ & \\
\hline \multicolumn{4}{|l|}{ Ethnicity } & \multirow[t]{6}{*}{0.051} \\
\hline Malay & $3823(43.7)$ & $1757(46.0)$ & $2066(54.0)$ & \\
\hline Chinese & $2957(33.8)$ & $1274(43.1)$ & $1683(56.9)$ & \\
\hline Indian & $822(9.4)$ & $357(43.4)$ & $465(56.6)$ & \\
\hline Other Malaysian & $97(1.1)$ & $35(36.1)$ & $62(63.9)$ & \\
\hline Foreigner & $1058(12.1)$ & $457(43.2)$ & $601(56.8)$ & \\
\hline \multicolumn{4}{|l|}{ HIV exposure risk factor } & \multirow[t]{6}{*}{$<0.001$} \\
\hline Homosexual & $3190(36.4)$ & $1090(34.2)$ & $2100(65.8)$ & \\
\hline Heterosexual & $3345(38.2)$ & $1616(48.3)$ & $1729(51.7)$ & \\
\hline Intravenous drug use & $1056(12.1)$ & $592(56.1)$ & $464(43.9)$ & \\
\hline Vertical transmission & $27(0.3)$ & $7(25.9)$ & $20(74.1)$ & \\
\hline Unknown & $1139(13.0)$ & $575(50.5)$ & $564(49.5)$ & \\
\hline \multicolumn{4}{|l|}{ Occupational group } & \multirow[t]{8}{*}{$<0.001$} \\
\hline Professional & $1216(13.9)$ & $367(30.2)$ & $849(69.8)$ & \\
\hline Non-professional & $3675(42.0)$ & $1824(49.6)$ & $1851(50.4)$ & \\
\hline Government officer & $332(3.8)$ & $105(31.6)$ & $227(68.4)$ & \\
\hline Self-employed & $477(5.4)$ & $215(45.1)$ & $262(54.9)$ & \\
\hline Student & $328(3.7)$ & $68(20.7)$ & $260(79.3)$ & \\
\hline Unemployed & $2147(24.5)$ & $1017(47.4)$ & $1130(52.6)$ & \\
\hline Unknown & $582(6.6)$ & $284(48.8)$ & $298(51.2)$ & \\
\hline \multicolumn{4}{|c|}{ Year of first presentation to care } & \multirow[t]{11}{*}{$<0.001$} \\
\hline 2007 & $379(4.3)$ & $216(57.0)$ & $163(43.0)$ & \\
\hline 2008 & $612(7.0)$ & $328(53.6)$ & $284(46.4)$ & \\
\hline 2009 & $563(6.4)$ & $317(56.3)$ & $246(43.7)$ & \\
\hline 2010 & $930(10.6)$ & $407(43.8)$ & $523(56.2)$ & \\
\hline 2011 & $887(10.1)$ & $389(43.9)$ & $498(56.1)$ & \\
\hline 2012 & $1070(12.2)$ & $437(40.8)$ & $633(59.2)$ & \\
\hline 2013 & $1122(12.8)$ & $482(43.0)$ & $640(57.0)$ & \\
\hline 2014 & $1099(12.5)$ & $443(40.3)$ & $656(59.7)$ & \\
\hline 2015 & $1003(11.5)$ & $380(37.9)$ & $623(62.1)$ & \\
\hline 2016 & $1092(12.5)$ & $481(44.0)$ & $611(56.0)$ & \\
\hline
\end{tabular}

aPercentage within each characteristic group.

${ }^{b}$ Percentage within late and non-late presentation to care.

" $p$-values refer to differences between groups with late and non-late presentation to care.

eIncludes natives from Sabah and Sarawak and indigenous people from Peninsular Malaysia. 
Table 2. Median baseline CD4 cell count

\begin{tabular}{|c|c|c|}
\hline Characteristics & $\begin{array}{c}\text { Median CD4 cell } \\
\text { count (cells/ } \mu \mathrm{l})(\mathrm{IQR})\end{array}$ & $p$ \\
\hline \multicolumn{2}{|l|}{ Gender } & \multirow[t]{3}{*}{$0.009^{a}$} \\
\hline Male & $233(336)$ & \\
\hline Female & $243(346)$ & \\
\hline \multicolumn{2}{|l|}{ Age group (years) } & \multirow[t]{5}{*}{$<0.001^{b}$} \\
\hline$\leq 30$ & $296(300)$ & \\
\hline $31-40$ & $198(336)$ & \\
\hline $41-50$ & $182(303)$ & \\
\hline$\geq 51$ & $153(272)$ & \\
\hline \multicolumn{2}{|l|}{ Ethnicity } & \multirow[t]{6}{*}{$<0.001^{b}$} \\
\hline Malay & $225(336)$ & \\
\hline Chinese & $241(328)$ & \\
\hline Indian & $246(433)$ & \\
\hline Other Malaysian & $299(386)$ & \\
\hline Foreigner & $241(315)$ & \\
\hline \multicolumn{2}{|l|}{ HIV exposure risk factor } & \multirow[t]{5}{*}{$<0.001^{b}$} \\
\hline Homosexual & $285(304)$ & \\
\hline Heterosexual & $211(346)$ & \\
\hline $\begin{array}{l}\text { Intravenous drug } \\
\text { use (IVDU) }\end{array}$ & $161(285)$ & \\
\hline Vertical transmission & $419(400)$ & \\
\hline \multicolumn{2}{|l|}{ Occupational group } & \multirow[t]{7}{*}{$<0.001^{b}$} \\
\hline Professional & 307 (297) & \\
\hline Non-professional & $202(325)$ & \\
\hline Government officer & $293(312)$ & \\
\hline Self employed & $237(367)$ & \\
\hline Student & $349(281)$ & \\
\hline Unemployed & $218(346)$ & \\
\hline
\end{tabular}

${ }^{a}$ Mann-Whitney $U$ test was used.

${ }^{b}$ Kruskal-Wallis $H$ test was used.

The yearly trends in median CD4 cell count at presentation to care are illustrated in Figure 1. Apart from the lowest point of 157 cells/ $\mu$ in 2009 and a decline in 2013 and 2016, the overall baseline CD4 cell count increased steadily from 176 cells $/ \mu$ l in 1997 to a peak of 271 cells $/ \mu$ in 2015 ( $p$ for trend $<0.001)$.

By HIV exposure risk factors (excluding vertical transmission), homosexual risk group consistently had the highest median baseline CD4 cell count over the period of 2007 to 2016, followed by heterosexual and IVDU risk groups (Figure 2). The median CD4 count of the homosexual risk group rose from 245 cells $/ \mu$ in 2007 to a high point of 339 cells/ $\mu \mathrm{l}$ in 2011, before dropping to 255 cells $/ \mu$ in 2016 ( $p$ for trend $0.005)$. Similarly, the heterosexual risk group saw growth in median CD 4 cell count from 179 cells/ $\mu \mathrm{l}$ in 2007 to 272 cells/ $\mu \mathrm{l}$ in 2015 , before decreasing to 218 cells/ $\mu$ in 2016 ( $p$ for trend

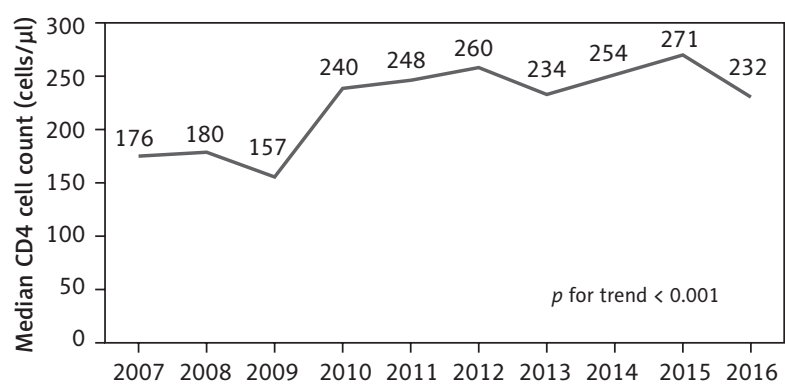

Figure 1. Median CD4 cell count at first presentation to care by calendar year

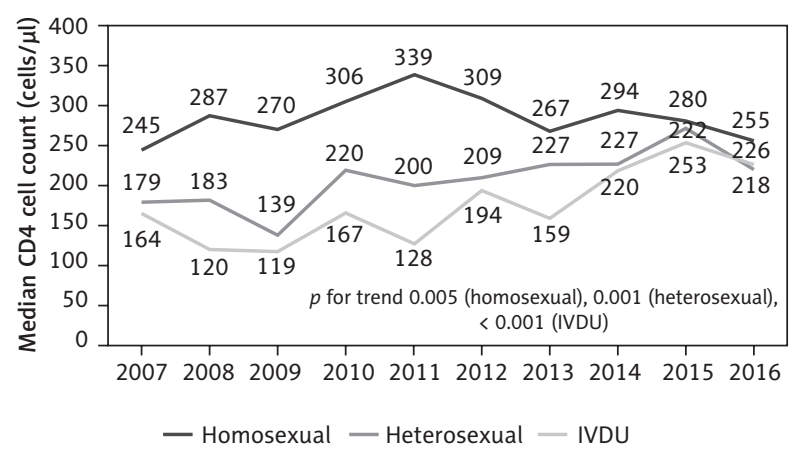

Figure 2. Yearly median CD4 cell count at first presentation to care stratified by HIV exposure risk factors

0.001). The IVDU risk group had persistently the lowest median CD4 count between 2007 and 2015. However, their median CD4 count managed to rise above 200 cells/ $\mu$ after 2014 and surpass the heterosexual group in 2016 with a median CD 4 count of 226 cells $/ \mu$ ( $p$ for trend $<0.001$ ). Overall, the gap in median CD4 count between these 3 risk groups narrowed over the past few years.

Median CD4 count at presentation to care, by gender, increased significantly from 167 cells/ $\mu$ to $228 \mathrm{cells} / \mu \mathrm{l}$ in males ( $p$ for trend $<0.001$ ); and from 187 cells $/ \mu$ to 242 cells $/ \mu$ in females with no statistical significance ( $p$ for trend 0.070 ) as shown in Figure 3. The difference in median CD4 count between genders decreased over the 10 -year period.

\section{Trends in proportion of patients with late presentation}

The overall proportion of patients who presented late to care significantly decreased over time from $57.0 \%$ in 2007 to $44.0 \%$ in 2016 ( $p$ for trend < 0.001) (Figure 4). A sharp decline of more than $12 \%$ of late presenters was noted from 2009 to 2010. The year 2015 had the lowest percentage of late presenters (37.8\%). By gender, the proportion of late presenters among males significantly decreased from $58.0 \%$ to $44.2 \%$ ( $p$ for trend $<0.001$ ) compared to $54.5 \%$ to $42.6 \%$ 


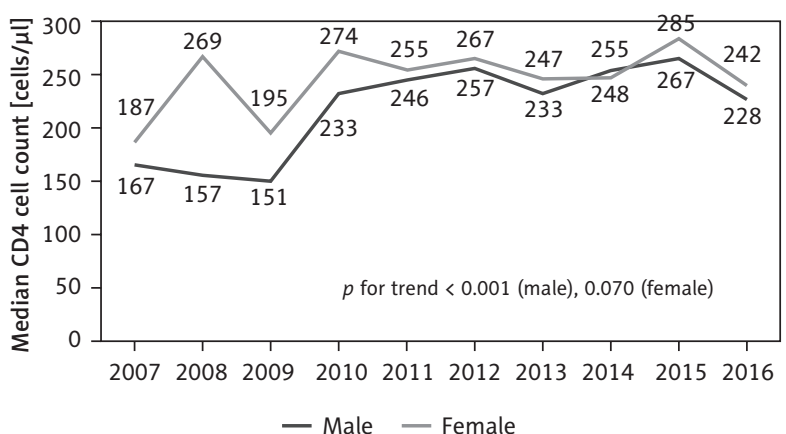

Figure 3. Yearly median CD4 cell count at first presentation to care stratified by gender

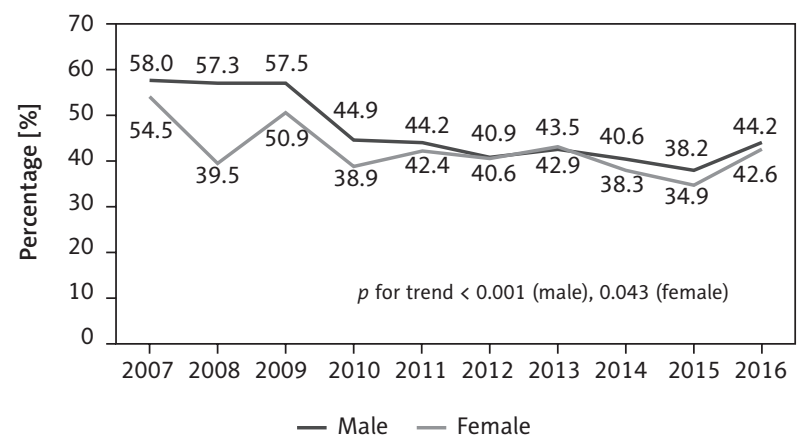

Figure 5. Yearly proportion of late presenters stratified by gender

among females ( $p$ for trend 0.043) (Figure 5). By HIV exposure risk factors, the proportion of patients with late presentation in intravenous drug user and heterosexual groups dropped from $61.3 \%$ to $41.4 \%$ ( $p$ for trend $<0.001$ ) and $57.7 \%$ to $46.7 \%$ ( $p$ for trend $<0.001$ ) respectively. In contrast, the homosexual group saw a significant increase of the proportion of late presenters from $37.5 \%$ to $40.4 \%$ ( $p$ for trend 0.018) (Figure 6).

\section{Discussion}

Early initiation of ART has led to prolonged life expectancy among HIV patients [23]. A large-scale randomized clinical trial known as the START (Strategic Timing of Anti-Retroviral Treatment) study has established that starting ART at CD4 count above 500 cells/ $\mu$ l significantly reduces the rates of serious AIDS and non-AIDS events [24]. The World Health Organization (WHO) has revised the HIV treatment guidelines to advocate early initiation of HAART regardless of CD4 cell count or clinical stage [25].

Despite the enormous attention being paid to early treatment of HIV/AIDS worldwide, timely HIV diagnosis and linkage to HIV care remain an uphill challenge in most countries including Malaysia. This is reflected by our

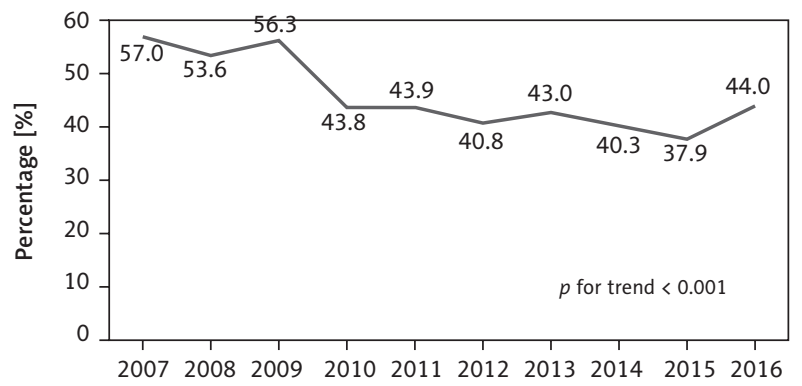

Figure 4. Proportion of patients with late presentation to care by calendar year

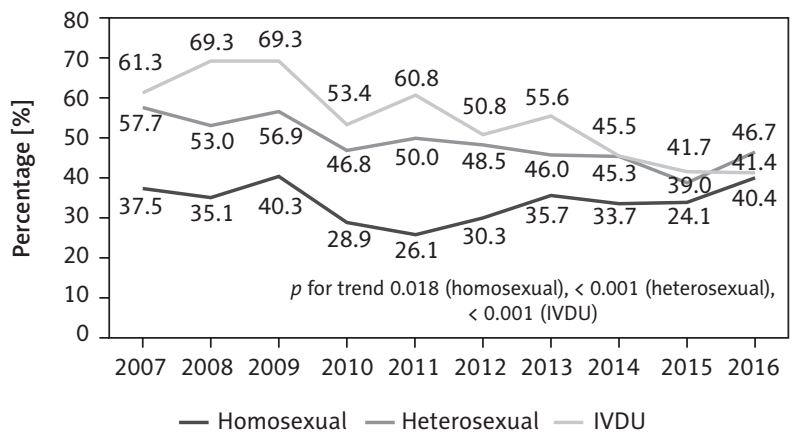

Figure 6. Yearly proportion of late presenters stratified by HIV exposure risk factors

study results which show that approximately $44 \%$ of new patients registered at the HIV Clinic in Sungai Buloh Hospital presented late to care with a CD4 cell count of less than 200 cells/ $\mu$ l, below the generally recognized threshold for opportunistic infections. Although the proportion of patients entering care late had declined since 2010, the percentage seemed to have reached a plateau, in the range of $40 \%$. These individuals lost the option to start therapy early, and missed opportunities to prevent further transmission and stop the progression of AIDS.

In our cohort, the yearly median baseline CD4 cell count ranged from 157 to 271 cells/ $\mu l$. Evidently, there was a surge of median CD4 counts after 2010, which coincided with the implementation of the National Strategic Plan on HIV/ AIDS (NSP) 2011-2015 that included a strategy to improve the quality and coverage of testing and treatment [26]. In an effort to scale up HIV testing and treatment, voluntary counselling and testing (VCT) services were made part of the Malaysian health services provided at no cost in 1,039 government health clinics and 141 government hospitals. The uptake of VCT services escalated more than 3-fold from 2011. The National Premarital Screening Program for Muslim couples was also introduced in 2010. In addition, the government through NGO also advocates regular HIV screening for key populations [27]. 
Although our results show a favourable trend of baseline CD4 cell count, we are still lagging behind developed countries. Based on a meta-regression among 169,007 patients in 44 studies from the United States and Europe, mean CD4 cell count at presentation to care increased by 1.5 cells/ $\mu$ l per year, from 307 cells/ $\mu$ in 1992 to 336 cells/ $\mu$ in 2011 [28]. In contrast, the highest median baseline CD4 cell count achieved in our hospital thus far was only 271 cells/ $\mu$ in 2015.

IVDU had been the main transmission factor for the HIV epidemic in Malaysia until it was superseded by sexual activity in 2011. As shown in our study, HIV-infected individuals with IVDU often present late to HIV care with low $\mathrm{CD} 4$ cell counts. In response to the persistent problems with heroin dependence and the emerging HIV/AIDS epidemic resulting from IVDU, Malaysia has introduced opiate agonist maintenance treatment (OMT) and a needle syringe exchange programme (NSEP), and started restructuring its mandatory institutional rehabilitation programme [29]. Individuals who enter into drug treatment programmes are likely to be screened for HIV and given ART early. Our results show a decreasing trend of the proportion of late presenters among IVDU patients. In fact, for the first time in 2016, there was a larger proportion of late presenters in the heterosexual group compared to the IVDU group.

Overall there were about $34 \%$ of homosexuals who presented late to care. Despite having the lowest proportion of late presenters compared to heterosexual and IVDU risk groups over the 10-year period, we have observed an increasing trend of homosexuals presenting late to care since 2011. The percentage of late presenters among homosexuals had reached as high as $40.4 \%$ by 2016 . The cause of this phenomenon needs to be examined further as the demographics of our homosexual cohort, which consisted of a predominantly young population, did not change significantly over the years. In general, homosexuality in Malaysia is not widely accepted from a social, cultural and religious point of view. Homosexual individuals often could not identify themselves by their sexual orientation freely because homosexuality is illegal and prohibited in Malaysia [30]. A study done on 3081 MSM (men having sex with men) in Spain showed an upward gradient of risk for late presentation as the time lag between the previous negative HIV test and the diagnostic test increased, underlining the importance for MSM to follow the recommendation of testing at least yearly [31].

To the best of our knowledge, this is the largest study regarding baseline CD4 cell count levels at presentation to care among HIV-positive patients in Malaysia. However, there are a few notable limitations to our study. As a single centre study, our findings may not be generalizable to other medical settings or regions of the country. Being a major HIV referral hospital in the state of Selangor and in close proximity to our capital city of Kuala Lumpur, our patients are largely from urban areas. Since HIV-infected patients with advanced disease are likely to be referred to a HIV specialist centre like ours, the late presenters in our cohort may be overrepresented. Asymptomatic patients in their early disease would probably continue follow-up in health clinics with a Family Medicine Specialist or private hospitals. Furthermore, we did not take into account other potential risk factors for late presentation such as education level, marital or partner status, spousal HIV status disclosure, alcohol dependence, etc. We also did not determine whether late presentation is due to delays in testing or in accessing HIV care.

\section{Conclusions}

Overall, the trends in baseline CD4 cells counts of newly diagnosed HIV patients are improving, but the proportion of late presenters is still significant. In order to achieve the goal of ending the AIDS epidemic in Malaysia by 2030, as committed in our new National Strategic Plan for Ending AIDS (NSPEA) 2016-2030 [32], innovative strategies are imperative to identify HIV infected individuals early in the course of their disease and link them promptly to care and treatment. We hope our study will provide a model for a multicentred study using our MATCH database, and for other HIV centres to investigate the specific risk factors of late presentations in the community they are serving.

\section{Conflict of interest}

The authors declare no potential conflicts of interest with respect to the research, authorship, and/or publication of this article.

\section{References}

1. Yamashita TE, Phair JP, Munoz A, et al. Immunologic and virologic response to highly active antiretroviral therapy in the Multicenter AIDS Cohort Study. AIDS 2001; 15: 735-746.

2. Cohen MS, Chen YQ, McCauley M, et al. Prevention of HIV-1 infection with early antiretroviral therapy. N Engl J Med 2011; 365: 493-505.

3. The Global AIDS Response Progress Report Malaysia, 2016.

4. Castilla J, Sobrino P, De La Fuente L, et al. Late diagnosis of HIV infection in the era of highly active antiretroviral therapy: consequences for AIDS incidence. AIDS 2002; 16: 1945-1951.

5. Chadborn T, Delpech V, Sabin CA, et al. The late diagnosis and consequent short-term mortality of HIV-infected heterosexuals (England and Wales, 2000-2004). AIDS 2006; 20: 2371-2379.

6. Chadborn TR, Baster K, Delpech VC, et al. No time to wait: how many HIV-infected homosexual men are diagnosed late and consequently die? (England and Wales, 1993-2002). AIDS 2005; 19 : 513-520.

7. Gupta SB, Gilbert RL, Brady AR, et al., on behalf of the CDSSAG. CD4 cell counts in adults with newly diagnosed HIV infection: results of surveillance in England and Wales, 1990-1998. AIDS 2000; 14: 853-861.

8. Girardi E, Aloisi MS, Arici C, et al., ICoNA Behavioural Epidemiology Study Group. Delayed presentation and late testing for HIV: demographic and behavioral risk factors in a multicenter study in Italy. J Acquir Immune Defic Syndr 2004; 36: 951-959.

9. Couturier E, Schwoebel V, Michon C, et al. Determinants of delayed diagnosis of HIV infection in France, 1993-1995. AIDS 1998; 12: 795-800.

10. Samet JH, Retondo MJ, Freedberg KA, et al. Factors associated with initiation of primary medical care for HIV-infected persons. Am J Med 1994; 97: 347-353. 
11. Girardi E, Sampaolesi A, Gentile M, et al. Increasing proportion of late diagnosis of HIV infection among patients with AIDS in Italy following introduction of combination antiretroviral therapy. J Acquir Immune Defic Syndr 2000; 25: 71-76.

12. Mugavero MJ, Castellano C, Edelman D, Hicks C. Late diagnosis of HIV infection: the role of age and sex. Am J Med 2007; 120: 370-373

13. Schwarcz S, Hsu L, Dilley JW, et al. Late diagnosis of HIV infection: trends, prevalence, and characteristics of persons whose HIV diagnosis occurred within 12 months of developing AIDS. J Acquir Immune Defic Syndr 2006; 43: 491-494.

14. McDonald AM, Li Y, Dore GJ, et al. Late HIV presentation among AIDS cases in Australia, 1992-2001. Aust N Z J Public Health 2003; 27: 608-613.

15. Samet JH, Freedberg KA, Stein MD, et al. Trillion Virion Delay: Time from testing positive for HIV to presentation for primary care. Arch Intern Med 1998; 158: 734.

16. Gay CL, Napravnik S, Eron JJ Jr. Advanced immunosuppression at entry to HIV care in the southeastern United States and associated risk factors. AIDS 2006; 20: 775-778.

17. Gardner LI Jr, Brundage JF, McNeil JG, et al. Predictors of HIV-1 disease progression in early-and late stage patients: the U.S. Army Natural History Cohort. Military Medical Consortium for Applied Retrovirology. J Acquir Immune Defic Syndr 1992; 5: 782-793.

18. Girardi E, Sabin CA, Monforte AD. Late diagnosis of HIV infection: epidemiological features, consequences and strategies to encourage earlier testing. J Acquir Immune Defic Syndr 2007; 46 Suppl 1: S3-S8.

19. Hocking JS, Rodger AJ, Rhodes DG, Crofts N. Late presentation of HIV infection associated with prolonged survival following AIDS diagnosis - characteristics of individuals. Int J STD AIDS 2000; 11: 503-508.

20. Lanoy E, Mary-Krause M, Tattevin P, et al. Frequency, determinants and consequences of delayed access to care for HIV infection in France. Antivir Ther 2007; 12: 89-96.

21. Masson CL, Sorensen JL, Phibbs CS, Okin RL. Predictors of medical service utilization among individuals with co-occurring HIV infection and substance abuse disorders. AIDS Care 2004; 16: 744-755.

22. Samet JH, Freedberg KA, Savetsky JB, et al. Understanding delay to medical care for HIV infection: the long-term non-presenter. AIDS 2001; 15: 77-85.

23. Samji H, Cescon A, Hogg RS, et al. North American AIDS Cohort Collaboration on Research and Design (NA-ACCORD) of IeDEA. Closing the gap: increases in life expectancy among treated HIV-positive individuals in the United States and Canada. PLoS One 2013; 8: e81355.

24. The Insight Start Study Group. Initiation of Antiretroviral Therapy in Early Asymptomatic HIV Infection. N Engl J Med 2015; 373: 795-807.

25. World Health Organization. Consolidated guidelines on the use of antiretroviral drugs for treating and preventing HIV infection. Second Edition. 2016.

26. National Strategic Plan on HIV and AIDS 2011-2015, Malaysia.

27. Global AIDS Response Progress Report, 2016, Malaysia.

28. Lesko CR, Cole SR, Zinski A, et al. A systematic review and metaregression of temporal trends in adult CD4 cell count at presentation to HIV care, 1992-2011. Clin Infect Dis 2013; 57: 1027-1037.

29. Singh D, Chawarski MC, Schottenfeld R, Vicknasingam B. Substance abuse and the HIV situation in Malaysia. J Food Drug Anal 2013; 21: S46-S51.

30. Laws of Malaysia, Act 574, Penal Code 377, as at 1 January 2015.

31. Diaz A, del Romero J, Rodriguez C, et al., for the EPI-VIH Study Group. Effects of region of birth, educational level and age on late presentation among men who have sex with men newly diagnosed with HIV in a network of STI/HIV counselling and testing clinics in Spain. Euro Surveill 2015; 20: 21088.

32. National Strategic Plan For Ending AIDS 2016-2030, Malaysia. 